\title{
(POSTER) Combining Design and Entrepreneurial Mindset Development: Improved Multifunctional Charging Station
}

\author{
Allison Zwickl \\ zwickla@uindy.edu \\ Payton Staman \\ stamanp@uindy.edu \\ Evan Parduhn \\ parduhne@uindy.edu \\ Jake Smith \\ smithjw@uindy.edu \\ David Olawale \\ olawaled@uindy.edu \\ See next page for additional authors
}

Follow this and additional works at: https://docs.lib.purdue.edu/aseeil-insectionconference

Part of the Electrical and Electronics Commons

Zwickl, Allison; Staman, Payton; Parduhn, Evan; Smith, Jake; Olawale, David; Spicklemire, Stephen; and Sarker, Rashedul, "(POSTER) Combining Design and Entrepreneurial Mindset Development: Improved Multifunctional Charging Station" (2019). ASEE IL-IN Section Conference. 6.

https://docs.lib.purdue.edu/aseeil-insectionconference/2019/posters/6 
Presenter Information

Allison Zwickl, Payton Staman, Evan Parduhn, Jake Smith, David Olawale, Stephen Spicklemire, and Rashedul Sarker 


\section{Combining Design and Entrepreneurial Mindset Development: Improved Multifunctional Charging Station}

Allison Zwickl, Jake Smith, Evan Parduhn, Payton Staman

\section{Introduction}

As the technology industry is growing exponentially, so are the number of charger types. It can become a hassle to have many cords for different types of devices. Creating a device that either eliminates charger cords or conveniently organizes them would diminish the frustration involved with recharging electronic devices.

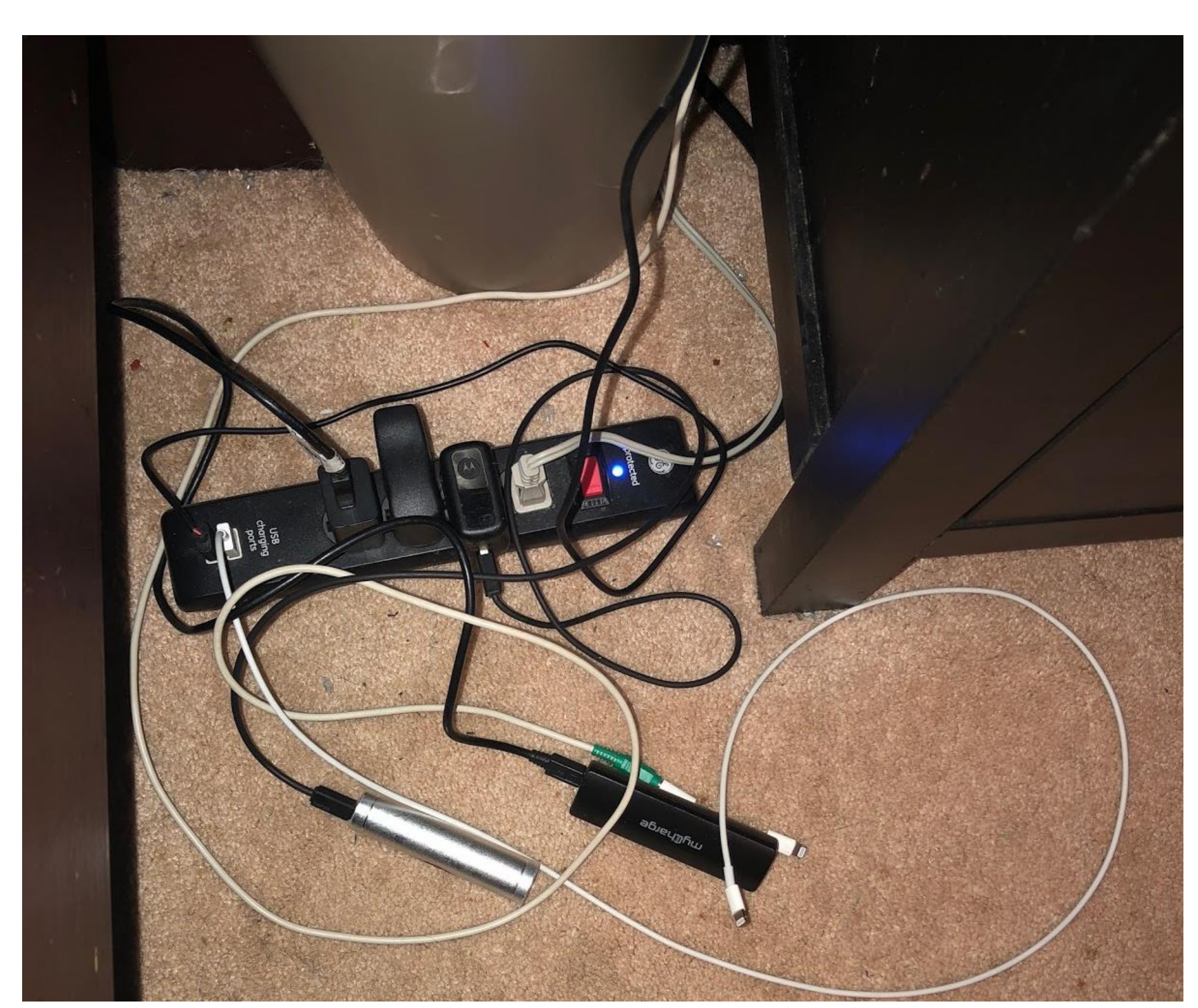

Figure 1: Actual Customer Charging Situation

\section{Opportunity}

Our vision, as a team, is to make a single charging station that is not only convenient to use, but has a sleek design, and is affordable.

\section{Customer Discovery}

44 total Interview

$90 \%: 10 \%$ face to face to Skype ${ }^{\circledR}$ interaction

Takeaway: There is a definite opportunity for a better solution!

Devices Per Household and Individuals<smiles>C1CCCCC1</smiles>

Individual

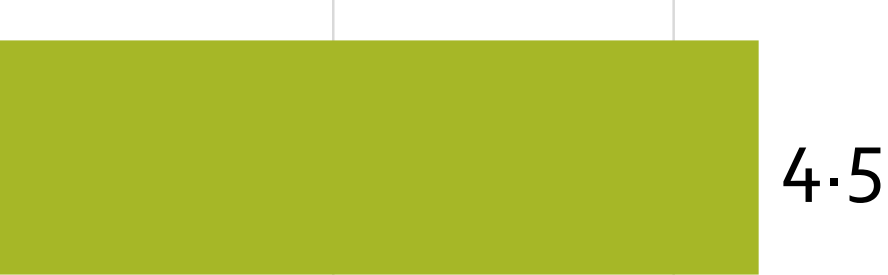

\section{Current Design on the Market}

Our product is unique, as there is already a similar design on the market. The current option is shown below.

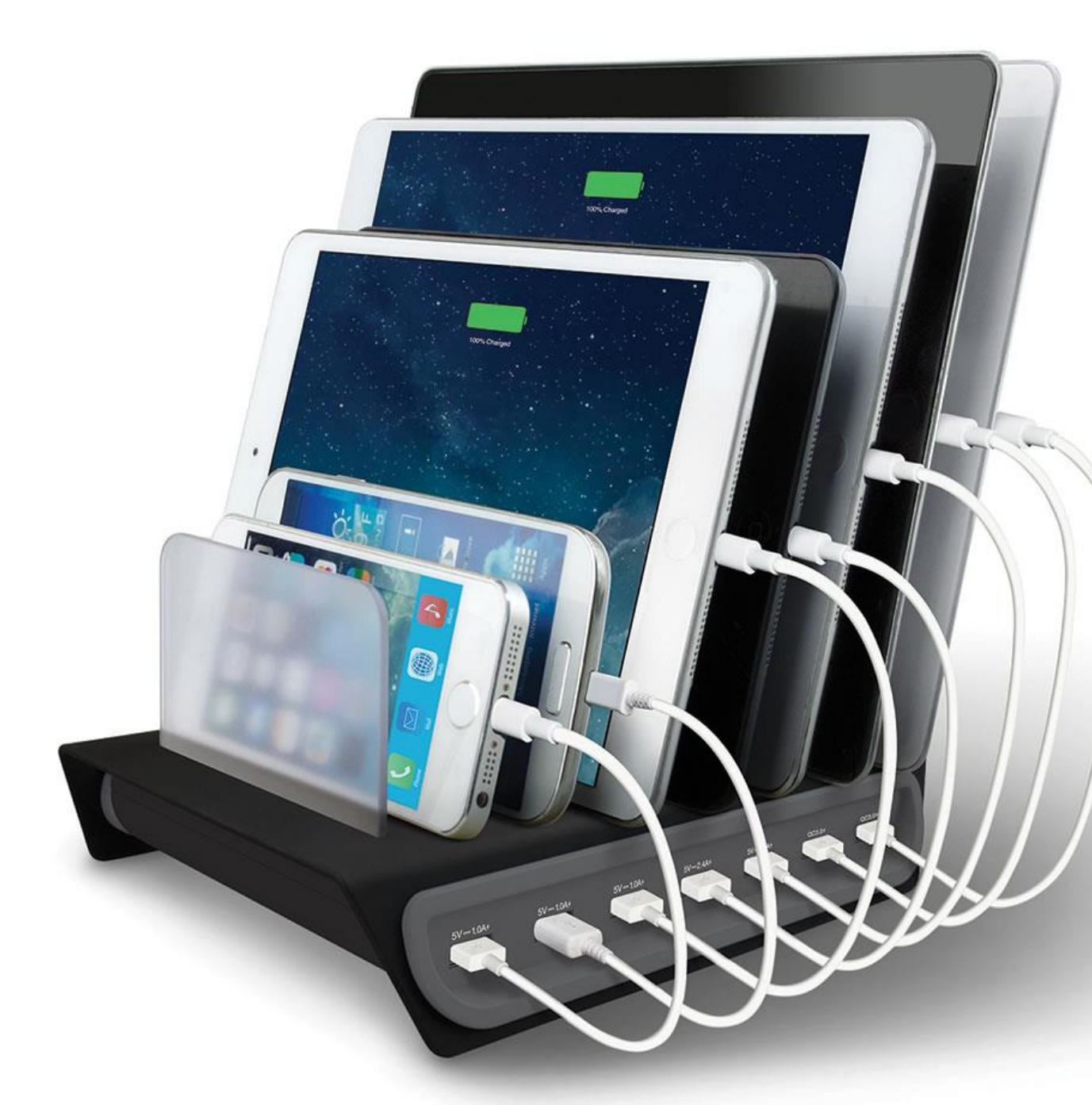

Figure 2: Current Charging Station

\section{Key Features}

Due to this being a product being already on the market, we came up with key features that would help our product stand out

Wireless Charging

Modular Add-Ons

Customizability

Based off of those features, we came up with this first design.

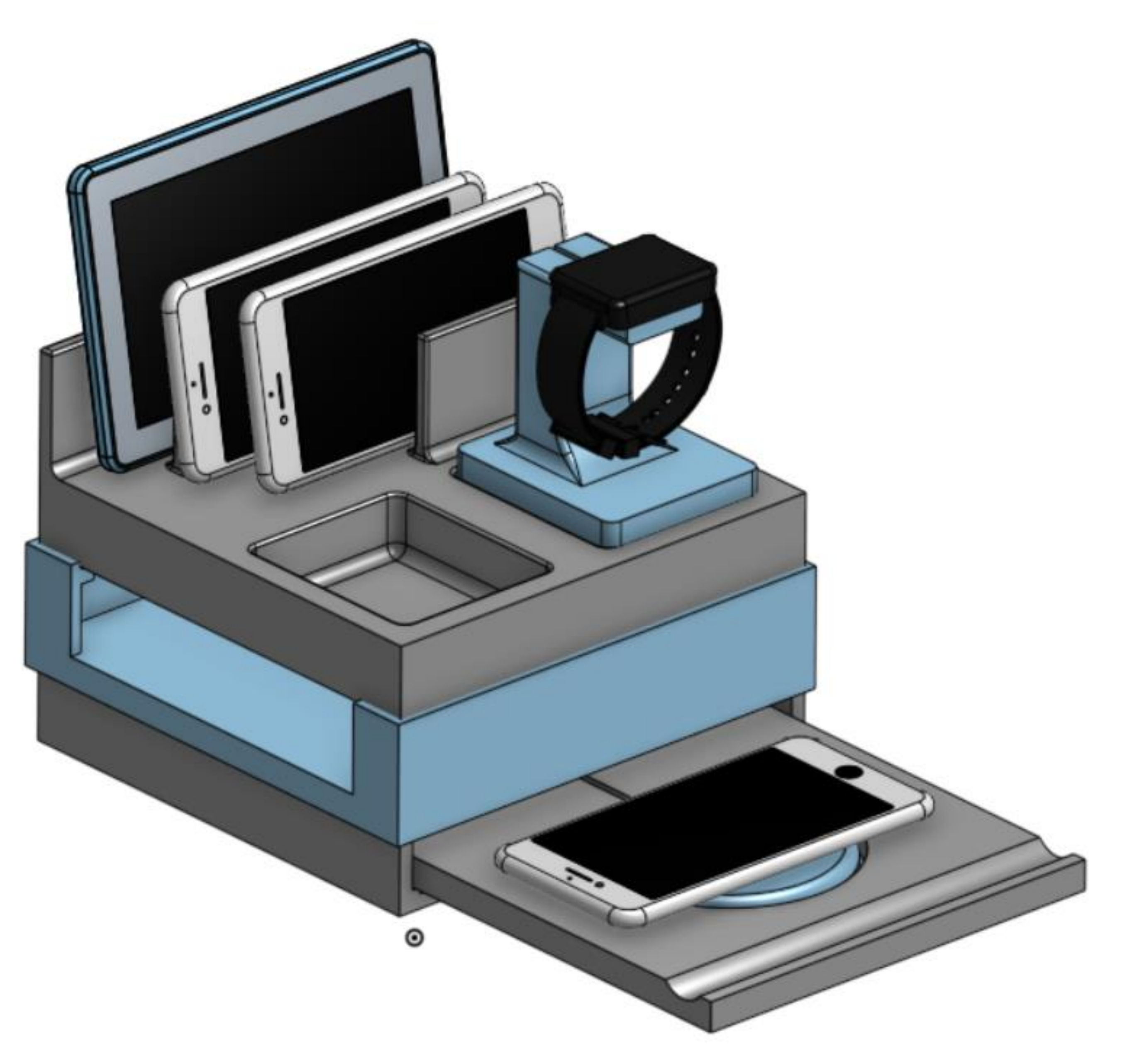

Figure 3: CHub 1.0

\section{Design Improvements}

After our first design was complete we had a few opportunities that would improve our design:

Distribute weight on top section

Add more security (hooks and latches) between the layers

Apply better cords management

From these opportunities we applied them to our next design, and came up with CHub 2.0.

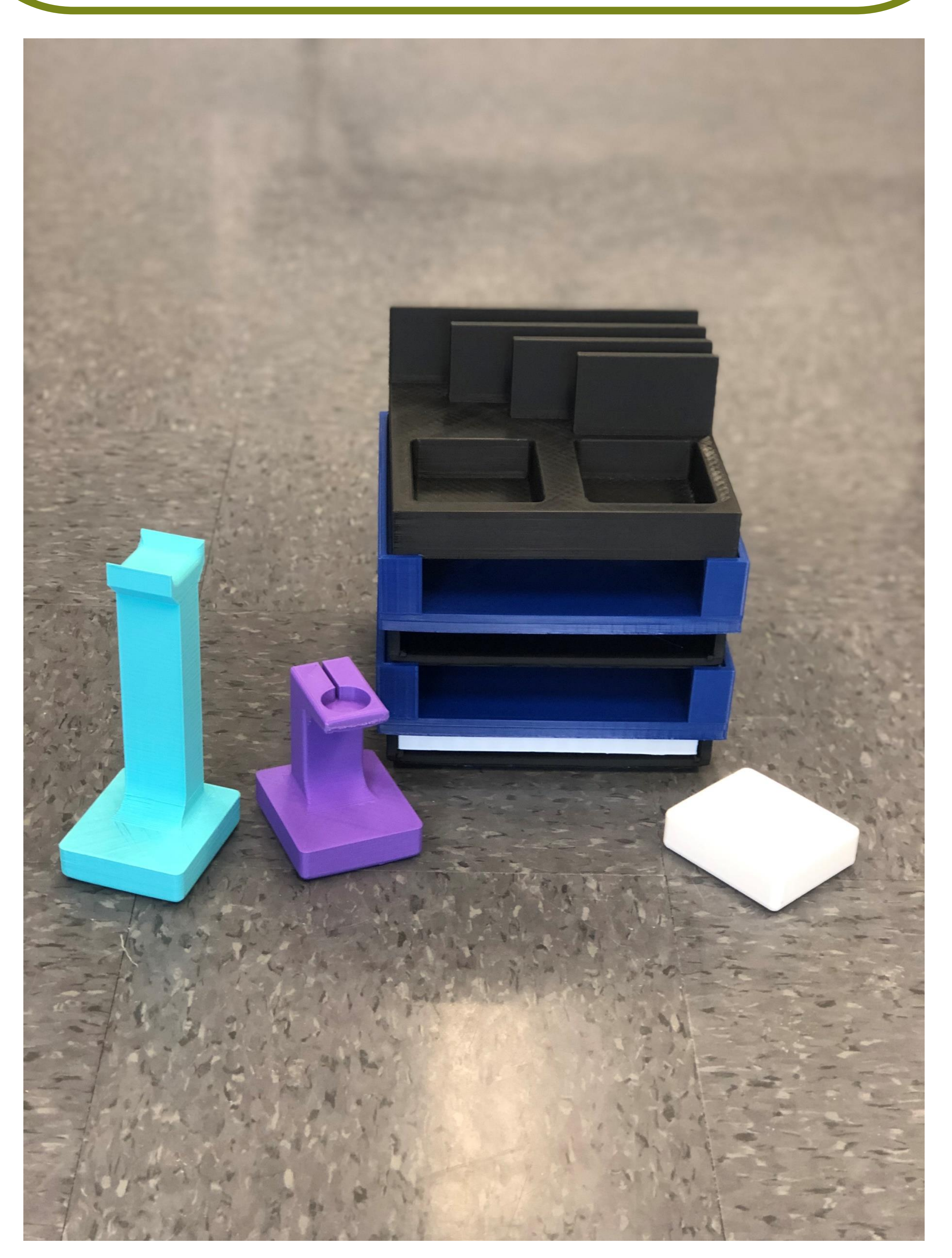

Figure 4: CHub 2.0

\section{Design Improvements}

It is more customizable, there are trays that can flip both upwards and downwards. That allows customers to be able to store cords, or bigger devices in the middle area.

For the final design CHub 3.0 we focused on: Improvement of wire management

Tighter fit between layers Modular Add-Ons

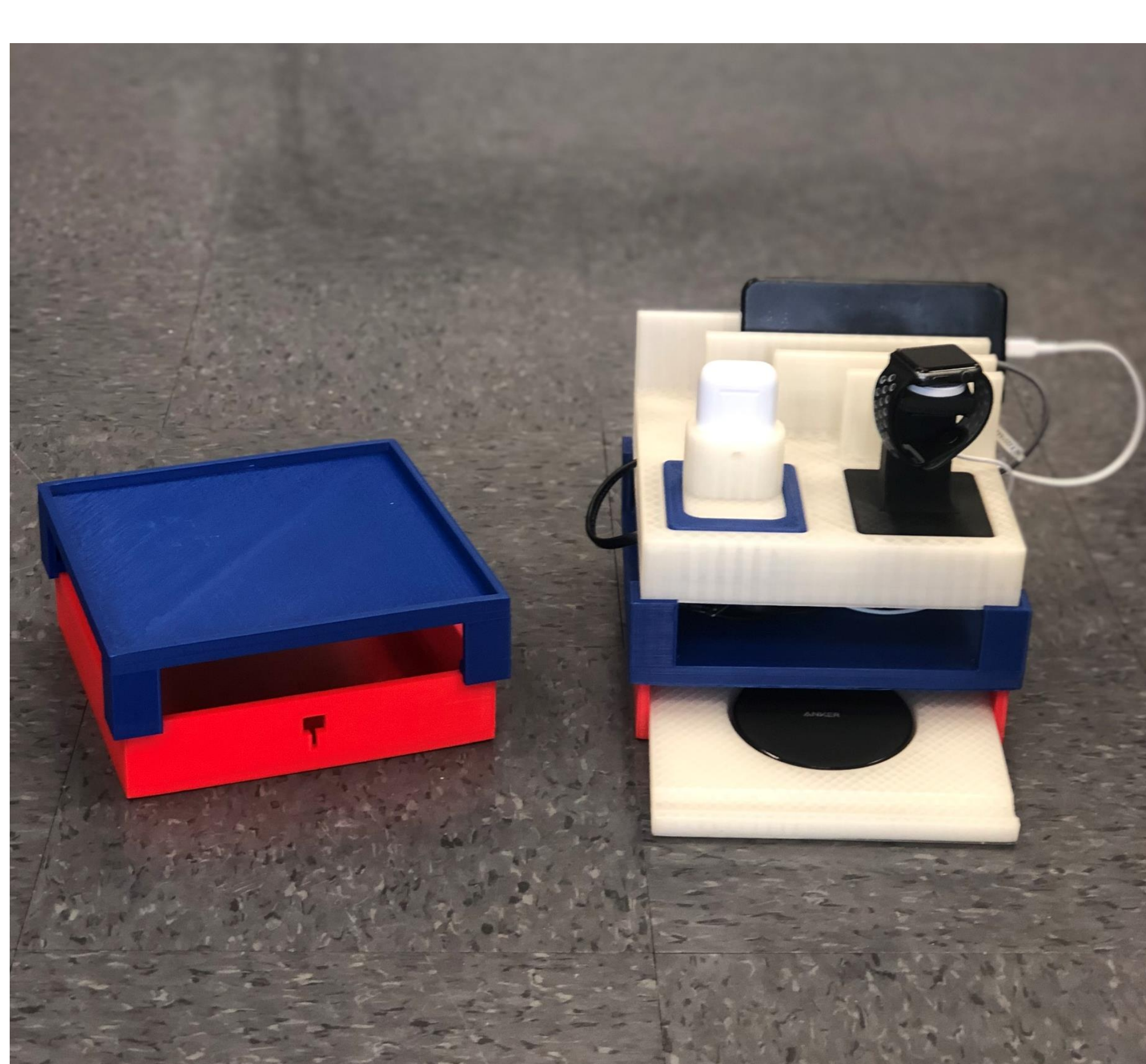

Figure 5: CHub 3.0

\section{Design Conclusion}

We continue to make improvements on our design. Currently we are working on finding a more sturdy material to make the charging station out of, to make it more durable. This is an ongoing process, and we continue to test all the new designs that we come up with.

\section{Testing Plan}

In order to determine if our project was ready to seen by customers we came up with a testing plan that our product needed to pass before coming up with our final design. Current testing plan includes structural stability, joint stability, and ease of assembling tests.

\section{Acknowledgements}

Thank you to all the faculty of the R.B. Annis School of Engineering, and a special thank you to our Faculty Team Committee, and our business mentor for their guidance and support throughout the project.

\section{References}

Udacity Course:https://www.udacity.com/schoolof-business

QFD:http://www.qfdonline.com/template-terms/

Amazon: www.amazon.com

FTC: Jose Sanchez, David Olawale, Steve Spicklemire, Rashedul Sarker 